\title{
Properties of Novel High Temperature Titanium Alloys for Aerospace Applications
}

\author{
John Mantione $^{1}$, Matias Garcia-Avila ${ }^{1}$, Matthew Arnold ${ }^{1}$, David Bryan ${ }^{1}$, John Foltz ${ }^{1}$ \\ ${ }^{1}$ ATI Specialty Materials
}

Monroe, NC 28110

\begin{abstract}
$\underline{\text { Abstract }}$
The attractive combination of strength and low density has resulted in titanium alloys covering 15 to $25 \%$ of the weight of a modern jet engine, with titanium currently being used in fan, compressor and nozzle components. Typically, titanium alloys used in jet engine applications are selected from the group of near alpha and alpha-beta titanium alloys, which exhibit superior elevated temperature strength, creep resistance and fatigue life compared to typical titanium alloys such as Ti-6Al-4V. Legacy titanium alloys for elevated temperature jet engine applications include Ti-5Al-2Sn-2Zr-4Mo-4Cr, Ti-6Al-2Sn-4Zr-2Mo-0.1Si and Ti-4Al4Mo-2Sn-0.5Si. Improving the mechanical behavior of these alloys enables improved component performance, which is crucial to advancing jet engine performance.
\end{abstract}

As a world leader in supplying advanced alloys of titanium, nickel, cobalt, and specialty stainless steels, ATI is developing new titanium alloys with improved elevated temperature properties. These improved properties derive from precipitation of secondary intermetallics in alpha-beta titanium alloys. ATI has developed several new alpha-beta titanium alloy compositions which exhibit significantly improved elevated temperature strength and creep resistance. This paper will focus on the effects of chemistry and heat treat conditions on the microstructure and resulting elevated temperature properties of these new aerospace titanium alloys.

\section{Introduction}

For decades Ti-6Al-2Sn-4Zr-2Mo-0.1Si (Ti-6242Si, UNS R54620) has been the workhorse alloy for high temperature aerospace applications due to its excellent elevated temperature strength, creep resistance and good weldability. Ti-6242Si is an alpha-beta titanium alloy patented in 1967 with a primary claim of creep resistance in excess of 150 hours at $1000^{\circ} \mathrm{F}\left(538^{\circ} \mathrm{C}\right)$ [1]. The primary application for this alloy has been jet engine components including compressor blades, disk and impellers, as well as airframe structure and skins near the engine subject to elevated temperature in service [2].

The creep resistance behaviour of titanium and titanium alloys at high temperature and under sustained loads depends primarily on microstructural morphology and secondary phase compositions. Titanium has two allotropic forms: a beta phase, which has a body centered cubic ("bcc") crystal structure; and an alpha phase, which has a hexagonal close packed ("hcp") crystal structure [2, 3]. Titanium alloys can be categorized depending on the fraction of alpha stabilizers and beta stabilizers in the alloy: alpha alloys, alphabeta alloys, and beta alloys. Main alpha stabilizers include $\mathrm{Al}, \mathrm{Sn}, \mathrm{Zr}, \mathrm{O}, \mathrm{N}$, and $\mathrm{C}$, while main beta stabilizing elements include Mo, $\mathrm{V}, \mathrm{Fe}, \mathrm{Cr}, \mathrm{Co}, \mathrm{Mn}, \mathrm{Nb}, \mathrm{Ni}, \mathrm{W}$ and Ta. A convenient way to characterize Ti alloys is through $\mathrm{Al}$ equivalency $\left(\mathrm{Al}_{\mathrm{eq}}\right)$ and $\mathrm{Mo}$ equivalency $\left(\mathrm{Mo}_{\mathrm{eq}}\right)$ using equations found in Figure 1 [2]. The ratio of alpha stabilizing and beta stabilizing elements in an alloy determine constituent phases and kinetics of phase precipitation in a Ti alloy. Typical alpha Ti alloys are commercially pure titanium (CP Ti), which are categorized by grade according to the oxygen content in the alloy. Alpha Ti alloys have excellent workability and weldability, and offer improvements in corrosion resistance compared to stainless steels. Alpha Ti alloys are typically used in petrochemical applications and in heat exchangers and tubing. Higher temperature resistant alpha-beta alloys such as ATI 6-2-4-2 alloy requires high volume fraction of alpha phase, so they contain higher amounts of alpha stabilizers such as $\mathrm{Al}$, Sn, and $\mathrm{Zr}$. On the other hand, beta alloys such ATI $21 \mathrm{~S}^{\mathrm{TM}}$ alloy and ATI $15 \mathrm{Mo}^{\mathrm{TM}}$ alloy contain higher amount of beta stabilizers such as Mo, Nb or V and lower amount of alpha stabilizers such as Al, Zr, or Sn. Figure 1 shows aerospace titanium alloys commonly produced at ATI categorized in terms of $\mathrm{Al}_{\mathrm{eq}}$ and $\mathrm{Mo}_{\mathrm{eq}}$. Most high-temperature titanium alloys take advantage of heat treatment to precipitate strengthening secondary alpha phase, and are between $5<\mathrm{Al}_{\mathrm{eq}}<9$ and $1<\mathrm{Mo}_{\mathrm{eq}}<10$. 


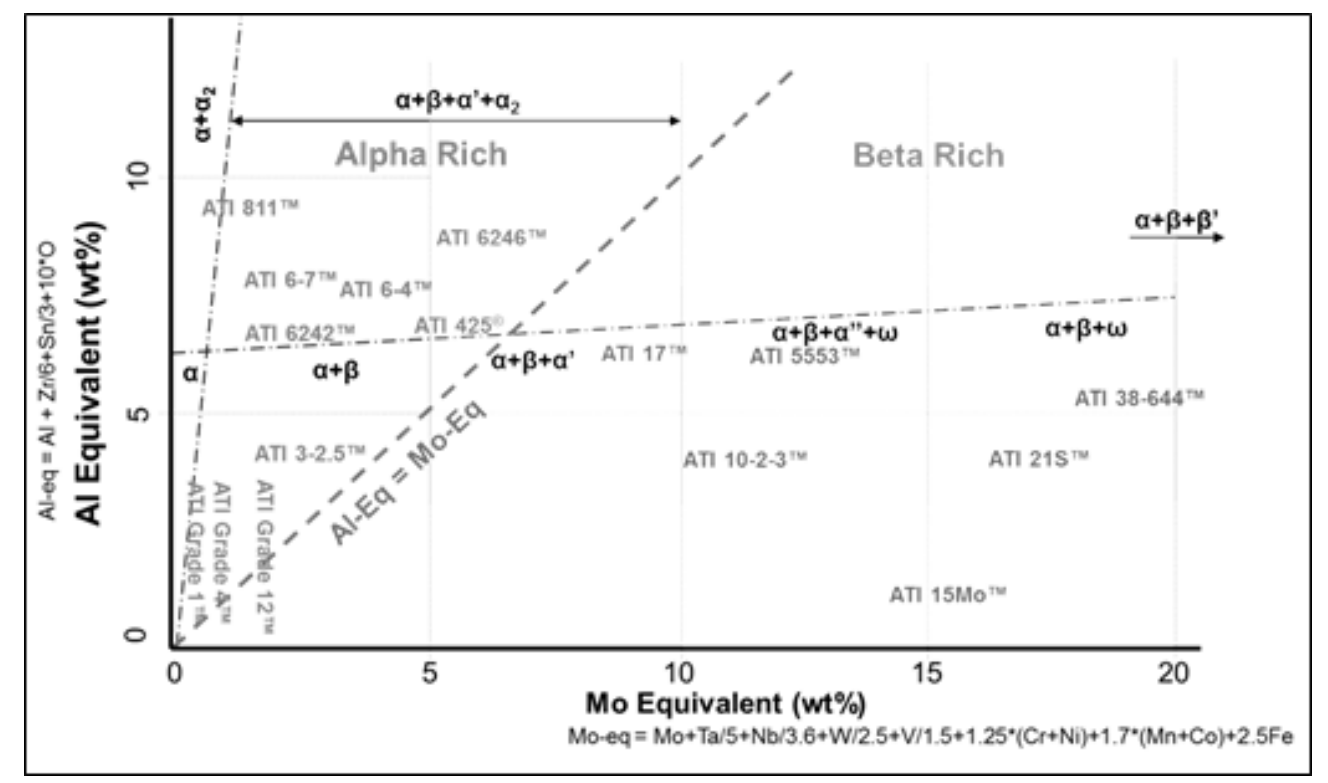

Figure 1: Plot of $\mathrm{Al}$ equivalency $\left(\mathrm{Al}_{\mathrm{eq}}\right)$ and $\mathrm{Mo}$ equivalency $\left(\mathrm{Mo}_{\mathrm{eq}}\right)$ for titanium alloys commonly produced at $\mathrm{ATI}$.

Predicted titanium phase fields obtained from Ref [4]. $\mathrm{Al}_{\mathrm{eq}}$ and $\mathrm{Mo}_{\mathrm{eq}}$ equations obtained from Ref. [2].

For ATI Alloys, ${ }^{\text {TM} / ~}{ }^{\circledR}$ trademarks of ATI Properties LLC

In general, beta titanium alloys exhibit poor elevated-temperature creep resistance due to the significant volume fraction of beta phase present at elevated temperatures. The beta phase does not resist creep due to its body centered cubic structure, which has a lower packing density and a significantly larger number of independent slip systems than the alpha phase [3]. These two aspects together translate often to higher diffusivities in beta phase than alpha phase. In alpha-beta titanium alloys, the volume fraction and size of the primary alpha particles can directly impact creep resistance as the hexagonal close packed structure has greater resistance to dislocation motion by diffusion assisted climb [3]. Additionally, alpha-beta titanium alloys containing silicon in greater than trace amounts will exhibit improved creep resistance due to the precipitation of silicides at the grain boundaries, but the silicides also result in a decrease in room temperature tensile ductility [3]. The reduction in room temperature tensile ductility that occurs with silicon addition limits the concentration of silicon that can be added to alpha-beta titanium alloys; typically to a $0.3 \%$ (by weight) maximum [3]. Furthermore, the optimum silicon content for maximum creep resistance in Ti-6242Si has been experimentally determined at 0.09 $\mathrm{wt} \%$ [5] with higher and lower silicon contents resulting in lower creep resistance.

The ATI team identified the elevated temperature strength and creep resistance of Ti-6242Si as an application-limiting property and executed a series of experiments to improve the elevated temperature strength and/or creep resistance of alpha rich alpha-beta titanium alloys with minor chemistry modifications. Prior research has documented the improvement in creep resistance, first by the addition of silicon and later by the reduction in iron and nickel residual content $[3,5,6,7]$. Some research using germanium as a solid solution strengthening addition to increase the alpha phase volume fraction has already been explored. Those experiments focused on using germanium as a primary alloying element in the rage of $1-4 \mathrm{wt} \%[8,9]$. The ATI team identified that smaller germanium additions on the order of $0.1 \mathrm{wt} \%$, similar to the optimum silicon addition in Ti-6242Si, were beneficial to elevated temperature properties without the negative effects reported for experiments at higher concentrations (patent applications submitted).

\section{Materials and Experiments}

A series of Plasma Arc Melt (PAM) 9 inch diameter electrodes (Figure 2) were produced from 100\% virgin raw materials including elemental additions, master alloys and titanium sponge. The heats included baseline Ti-6242Si chemistry and two Ti6242Si heats with 0.1-0.2 wt\% germanium additions. Each electrode was conditioned and Vacuum Arc Remelted (VAR) to produce 10 inch diameter ingots each weighing $450 \mathrm{lb}$. Each ingot was converted to a 3 inch diameter billet on a 1000 US-ton open die forge press by an upset and draw practice which included a beta grain refinement step and a final alpha-beta draw. The 3 inch diameter billet was cut into $2.5 \mathrm{lb}$. mults and upset forged in the alpha-beta regime into a 4.75 inch diameter pancakes for testing (Figure 3). The forged pancakes were solution treated at $1785^{\circ} \mathrm{F}\left(974^{\circ} \mathrm{C}\right)$ for 4 hours, water quenched to room temperature and aged at $1100^{\circ} \mathrm{F}\left(593^{\circ} \mathrm{C}\right)$ for 8 hours followed by an air cool (STA heat treatment). 


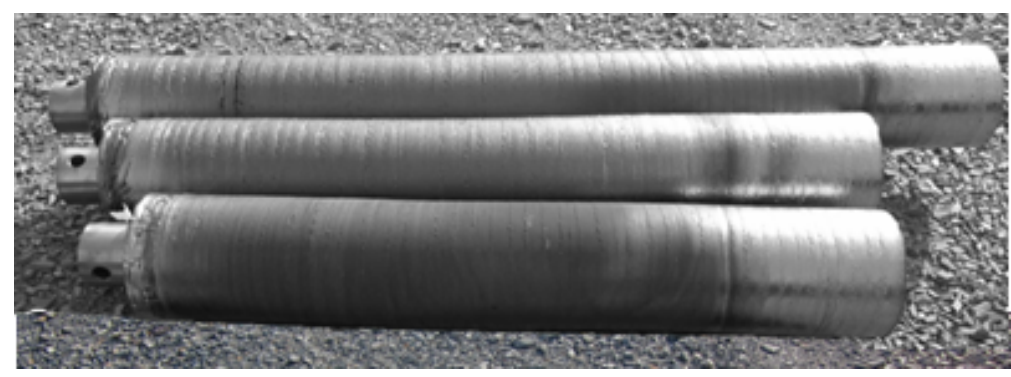

Figure 2: Plasma Arc Melt (PAM) 9 inch diameter electrodes.

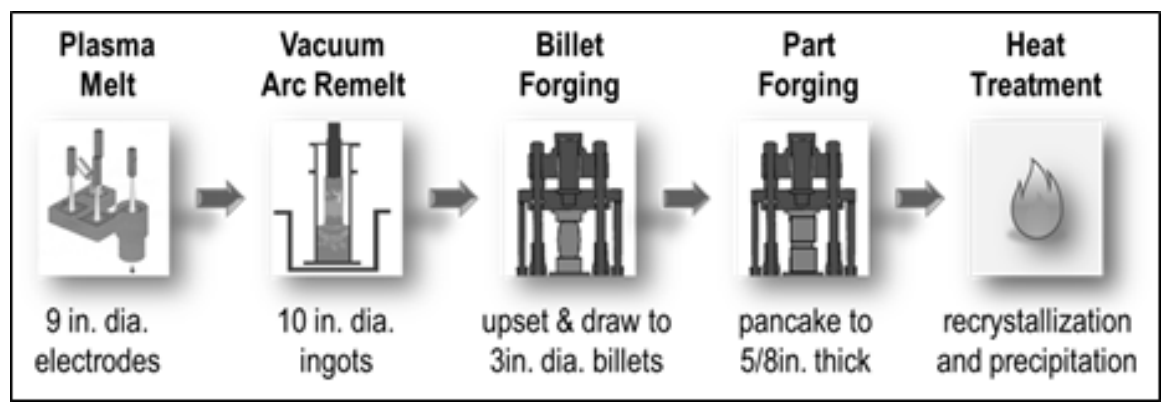

Figure 3: Ingot to test sample manufacturing process.

Mechanical testing of the forged and heat treated pancakes consisted of tensile testing in accordance with ASTM E8 and ASTM E21 and creep testing in accordance with ASTM E-139. Beta transus determination was performed using the DSC-TGA method. Bulk chemistry was analyzed using XRF, ICP-OE, IGF or combustion analysis as applicable. The mechanical and chemical testing was performed at ATI Specialty Materials or an external NADCAP certified laboratory. Microscopy and electron dispersive spectroscopy (EDS) was performed using a Hitachi SU6600 field emission scanning electron microscope (SEM) using a backscattered electron detector used for imaging and chemical analysis of polished and un-etched samples. Quantification of the microstructure was done using 3rd party image quantification tools. Thermodynamic simulation was performed using a commercially available CALPHAD tool (Pandat ${ }^{\mathrm{TM}}$ with the PanTitanium database from CompuTherm LLC) to predict the beta transus and equilibrium phases for comparison with experimental data.

\section{$\underline{\text { Results }}$}

Chemistry of the experimental heats was consistent through the length and thickness of the ingot but slightly below the nominal Ti-6242Si chemistry (Figure 4). The Beta Transus predictions were within $+/-3^{\circ} \mathrm{C}$ of the DSC-TGA experimental results (Figure 5) and the slightly elevated transus of heat B5P41 is related to the elevated oxygen content $(0.16 \mathrm{wt} \%)$ which slightly increased the Al-eq compared with the other two experimental heats. Room and elevated temperature tensile properties were also consistent between the three experimental heats (Figure 6). Elevated temperature creep resistance improved as a function of increasing germanium content; both in total strain at 125 hours and in steady state creep rate (Figure 6). The microstructure of the pancake forging after heat treatment is the typical equiaxed and elongated primary alpha particles in a transformed beta matrix necessary for a good balance of strength, ductility and creep resistance (Figure 7). Examination of the creep test samples after exposure revealed $\sim 1 \mathrm{~mm}$ diameter precipitates enriched in $\mathrm{Zr}-\mathrm{Si}-\mathrm{Ge}$ and depleted in Ti-Al-Mo within the primary alpha particles (Figure 8).

\begin{tabular}{|c|c|c|c|c|c|c|c|c|c|}
\hline & $\begin{array}{c}\text { Al } \\
(\mathbf{w t} \%)\end{array}$ & $\begin{array}{c}\text { Sn } \\
(\mathbf{w t} \%)\end{array}$ & $\begin{array}{c}\mathbf{Z r} \\
(\mathbf{w t} \%)\end{array}$ & $\begin{array}{c}\text { Mo } \\
(\mathbf{w t} \%)\end{array}$ & $\begin{array}{c}\text { Si } \\
(\mathbf{w t} \%)\end{array}$ & $\mathbf{O}(\mathbf{w t} \%)$ & $\begin{array}{c}\text { Ge } \\
(\mathbf{w t \%})\end{array}$ & Aleq & Moeq \\
\hline $\begin{array}{c}\text { Ti-6242Si } \\
\text { Nominal }\end{array}$ & 6 & 2 & 4 & 2 & 0.1 & 0.12 & 0 & 8.5 & 2.0 \\
\hline B5P41 & 5.9 & 1.8 & 4.1 & 1.9 & 0.07 & 0.16 & 0 & 8.8 & 1.9 \\
\hline B5P42 & 5.9 & 1.9 & 4.0 & 1.8 & 0.06 & 0.12 & 0.1 & 8.4 & 1.8 \\
\hline B5P43 & 5.9 & 1.9 & 3.9 & 1.9 & 0.07 & 0.13 & 0.2 & 8.5 & 1.9 \\
\hline
\end{tabular}

Figure 4: Chemistry of the experimental ingots.

\begin{tabular}{|c|c|c|c|}
\hline \multicolumn{4}{|c|}{ Beta Transus } \\
\hline & $\begin{array}{c}\text { DTA } \\
\left({ }^{\circ} \mathrm{F}\right)\end{array}$ & $\begin{array}{c}\text { DTA } \\
\left({ }^{\circ} \mathrm{C}\right)\end{array}$ & $\begin{array}{c}\text { CALPHAD } \\
\left({ }^{\circ} \mathrm{C}\right)\end{array}$ \\
\hline $\begin{array}{c}\text { Ti-6242Si } \# \\
\text { typical }\end{array}$ & $\begin{array}{c}1825 \\
(+/-25)\end{array}$ & $\begin{array}{c}990 \\
(+/-15)\end{array}$ & - \\
\hline & & & \\
\hline
\end{tabular}




\begin{tabular}{|l|l|l|l|} 
B5P41 & 1855 & 1013 & 1010 \\
\hline B5P42 & 1835 & 1002 & 1002 \\
\hline B5P43 & 1840 & 1004 & 1002 \\
\hline
\end{tabular}

Figure 5: Beta Transus as determined by differential thermal analysis (DTA)

and thermodynamic calculation (CALPHAD).

\begin{tabular}{|c|c|c|c|c|c|c|c|}
\hline Temperature & Heat \# & $\begin{array}{l}\text { UTS } \\
\text { (ksi) }\end{array}$ & $\begin{array}{c}\text { YS } \\
\text { (ksi) }\end{array}$ & $\begin{array}{c}\text { \%Elong } \\
\text { (4D) }\end{array}$ & \%RA & $\begin{array}{c}\text { \%Creep Strain } \\
52 \mathrm{ksi} \text { load } \\
125 \text { hours }\end{array}$ & $\begin{array}{l}\text { Steady State } \\
\text { Creep Rate } \\
(\% / h) \times 10^{-4}\end{array}$ \\
\hline \multirow[t]{3}{*}{$72^{\circ} \mathrm{F}$} & B5P41 & 175 & 158 & 14 & 41 & & \\
\hline & B5P42 & 174 & 153 & 15 & 38 & & \\
\hline & B5P43 & 178 & 157 & 14 & 39 & & \\
\hline \multirow[b]{3}{*}{$\left(482^{\circ} \mathrm{C}\right)$} & B5P41 & 126 & 99 & 19 & 63 & 0.20 & 7.9 \\
\hline & B5P42 & 127 & 95 & 18 & 58 & 0.16 & 3.5 \\
\hline & B5P43 & 130 & 95 & 17 & 59 & 0.13 & 3.4 \\
\hline
\end{tabular}

Figure 6: Room and elevated temperature tensile and creep properties.

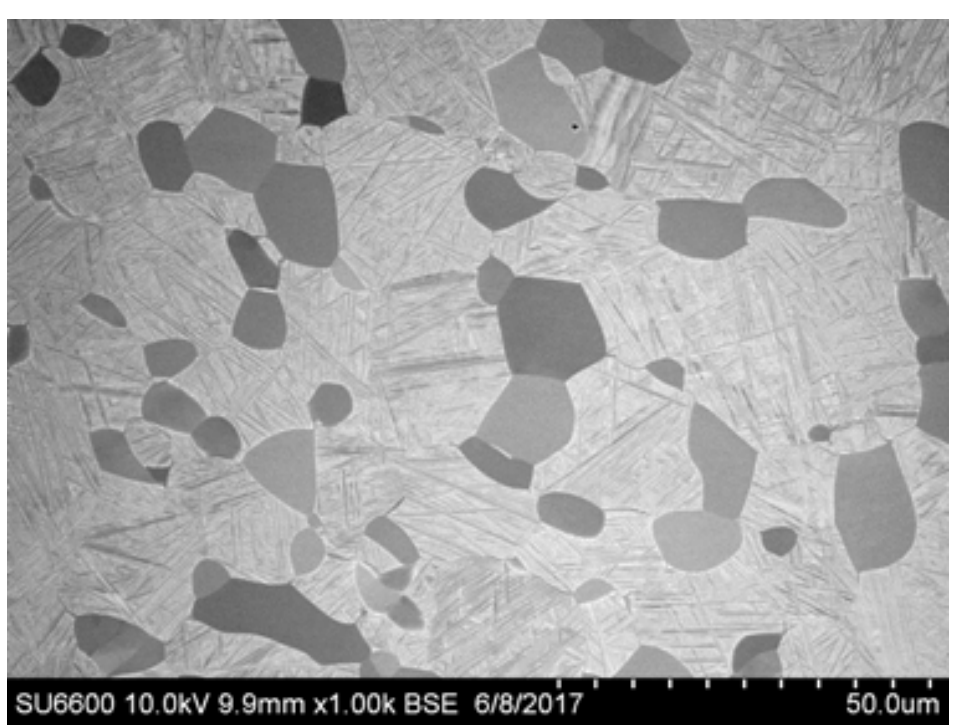

Figure 7: BSE image of alpha particles in a transformed matrix:

heat B5P43 after pancake forging and STA heat treatment. 


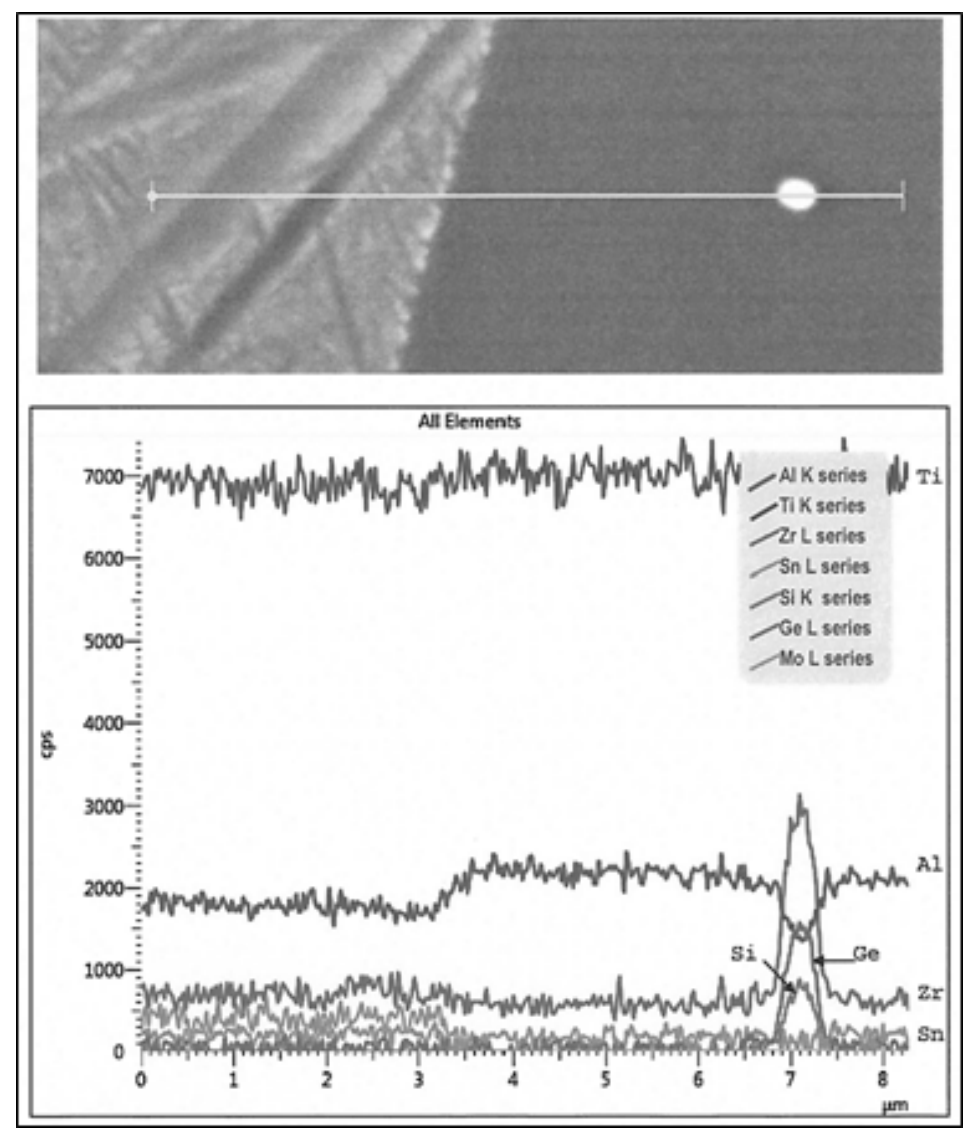

Figure 8: BSE image and EDS line scan of $\mathrm{Zr-Si-Ge} \mathrm{particle} \mathrm{in} \mathrm{heat}$

B5P43 after pancake forging, heat treatment and creep testing.

\section{Discussion}

The role of $(\mathrm{Ti}, \mathrm{Zr})_{5} \mathrm{Si}_{3}$ silicide precipitation in reducing the steady state creep rate of alpha-beta titanium alloys has been examined and well documented by Neal, Fox [10] and Paton, Mahoney [11]. The precipitation of a $\mathrm{Ti}_{6} \mathrm{Ge}_{5}$ or $\mathrm{TiGe}_{2}$ germanide in a Ti-Ge binary and the precipitation of a $\mathrm{Ti}_{6}(\mathrm{Si}, \mathrm{Ge})_{5}$ germanide-silicide in a Ti-Ge-Si system have been studied by Thomas [12]. The full range of Ti-Ge compositions including the $\mathrm{Ti}_{5} \mathrm{Ge}_{3}$ were confirmed by Liu [13]. In this study, the addition of small amounts of germanium to Ti-6242Si resulted in a zirconium germanide-silicide precipitate which is likely in the form $(\mathrm{Ti}, \mathrm{Zr})_{5}(\mathrm{Ge}, \mathrm{Si})_{3}$. Prior work by Kitashima [8] using higher germanium content demonstrated a similar Ti-Zr-Ge-Si precipitate, but the higher Ge content (up to $4 \mathrm{wt} \%$ ) resulted in a significant increase in tensile strength and ductility which was not evident in the present study with a Ge content less than $1 \mathrm{wt} \%$. The experimental data for Ti-6242Si with Ge additions of 0.1 and $0.2 \mathrm{wt} \%$ exhibited significant improvement in steady state creep rate and total creep strain as a function of increasing Ge content. Apparent activation energies for steady state creep were calculated from creep tests performed at $900^{\circ} \mathrm{F}\left(482^{\circ} \mathrm{C}\right)$ and $950^{\circ} \mathrm{F}\left(510^{\circ} \mathrm{C}\right)$ (Figure 9). The calculated activation energy for the baseline Ti-6242Si heat B5P41is slightly higher than the 304-316 kJ/mol reported by Es-Souni [14], lower than the 360-420 kJ/mol reported by Bania and Hall [15] and agree with the 308-374 kJ/mol reported by Mishra [3] [7]. The experimental activation energy for the Ti-6242Si+Ge heats B5P42 and B5P43 are significantly higher at 425-465 kJ/mol. (Figure 9). 


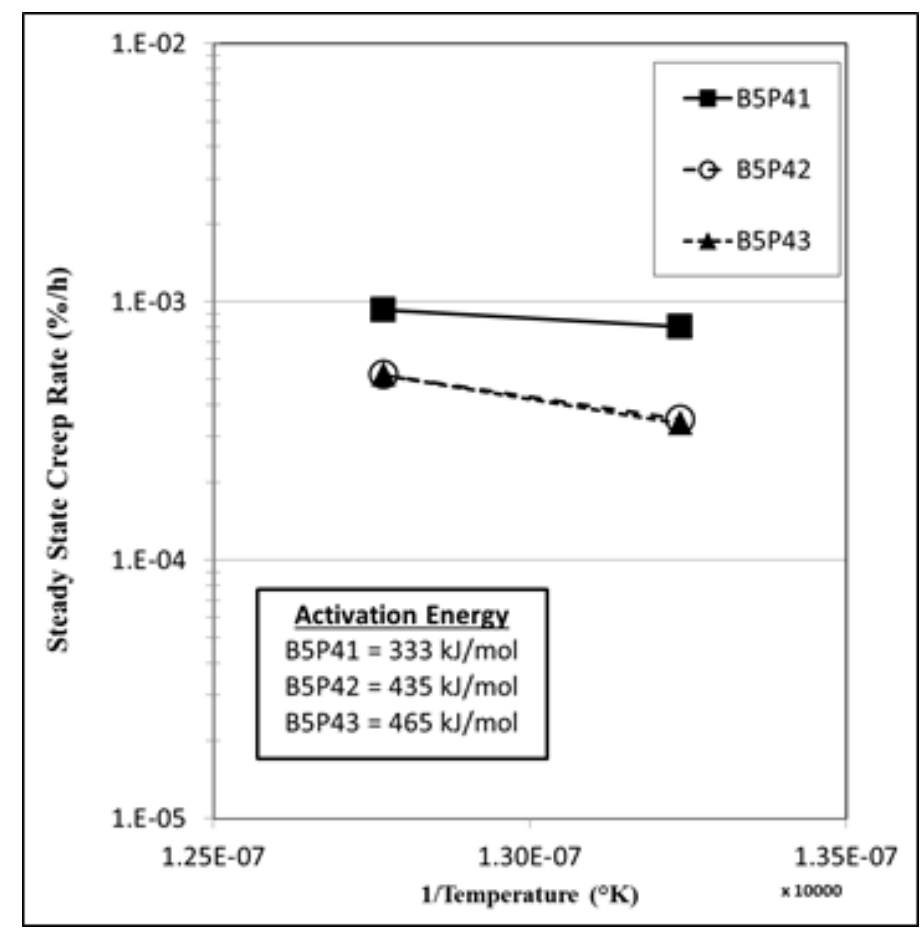

Figure 9: Natural log steady state creep rate as a function of inverse temperature.

Apparent activation energy calculated from the slope.

\section{$\underline{\text { Conclusions }}$}

In this study, systematic addition of germanium to Ti-6242Si alloy was achieved using $450 \mathrm{lb}$. double melted titanium ingots. These ingots were forged in an open-die press to simulate typical processing of titanium billet and titanium forgings. In all cases, the addition of a small amount of germanium (less than $1 \mathrm{wt} \%$ ) to the Ti-6242Si alpha-beta titanium alloy resulted in the formation of a Ti-Zr germanide-silicide precipitate which improved creep resistance at $900-950^{\circ} \mathrm{F}\left(482-510^{\circ} \mathrm{C}\right)$ without a negative impact to strength or ductility. Further analysis is warranted to determine the composition of the germanide precipitate and the mechanism of creep resistance enhancement. Nevertheless, application of these improved titanium alloys into jet engine components will translate to an increase in jet engine performance.

\section{$\underline{\text { References }}$}

[1] R.E.Peebles, "Titanium Base Alloy". Steubenville, OH Patent 3,343,951, 1967.

[2] G.Welsch, R.Boyer and E.W.Collings, Material Properties Handbook: Titanium Alloys, ASM International, 1994, pp. 5-11,337-375.

[3] G.Lutjering and J.C.Williams, Titanium - Engineering Materials and Processes, Springer, 2007, pp. 259270,279-282.

[4] R.C.Hansen and A.Raman, "Zeitschrift fuer Metallkunde / Materials Research and Advanced Techniques, 61 (2)," 1970, pp. 115-120.

[5] H.W.Bomberger and S.R.Seagle, "Titanium base alloy and method of improving creep properties". Niles, OH Patent US 3,833,363, 1974.

[6] R.W.Hayes, G.B.Viswanathan and M.J.Mills, "Creep Behavior of Ti-6Al-2Sn-4Zr-2Mo: I. The effect of nickel on creep deformation and microstructure," Acta Materialia, vol. 50, pp. 4953-4963, 2002.

[7] H.Mishra, D.V.V.Satyanarayana, T.K.Nandy and P.K.Sagar, "Effect of trace impurities on the creep behavior of a near alpha titanium alloy," Scripta Materialia, vol. 59, pp. 591-594, 2008. 
[8] T.Kitashima, K.S.Suresh and Y.Yamabe-Mitarai, "Effect of germanium and silicon additions on the mechanical properties of a near alpha titanium alloy," Mat. Sci. \& Engr. A, vol. 597, pp. 212-218, 2014.

[9] G.S.Hall, S.R.Seagle and H.B.Bomberger, "Development of a 900F titanium alloy," AFML-TR-73-37, 1973.

[10] D.F.Neal and S.P.Fox, "The influence of silicon and silicides on the properties of near alpha titanium alloys," in Titanium 92, TMS, 1993.

[11] N.E.Patton and M.W.Mahoney, "Creep in titanium silicon alloys," Met. Trans. A, vol. 7A, pp. 16851694, 1976.

[12] O.Thomas, S.Delage, F.M.d'Heurle and G.Scillia, "Reaction of titanium with germanium and silicon germanium alloys," Appl. Phys. Let., vol. 54, no. 3, pp. 228-230, 1989.

[13] D.Liu, H.Yan, X.Yuan, Y.Chung, Y.Du, H.Xu, L.Liu and P.Nash, "Thermodynamic modeling of the Ge-Ti system supported by key experiment," Thermochimica Acta, vol. 521, pp. 148-154, 2011.

[14] M.Es-Souni, "Primary, secondary and anelastic creep of a high temperature near alpha Ti alloy Ti6242Si," Materials Characterization, vol. 45, pp. 153-164, 2000.

[15] P.Bania and J.Hall, "Creep Studies of Ti6242Si alloy," Titanium Science and Technology, Frankfurt: Deutsche Gesellchaft fur Metallkunde, pp. Vol. 4, 2371-2378, 1985. 